ВОРОНОВ Виктор Васильевич - доктор социологических наук, профессор, ведущий научный сотрудник Института социологии Федерального научно-исследовательского социологического центра РАН (117218, Россия, г. Москва, ул. Кржижановского, 24/35, корn. 5; voronov@isras.ru) ШУЛЕПИН Михаил Владимирович - аспирант Института социологии Федерального научно-исследовательского социологического центра РАН(117218, Россия, г. Москва, ул. Кржижановского, 24/35, кopn.5; mihailshulepin@mail.ru)

\title{
О ДОПОЛНИТЕЛЬНОМ ПРОФЕССИОНАЛЬНОМ ОБРАЗОВАНИИ В ЗАРУБЕЖНЫХ ТЕРРИТОРИАЛЬНЫХ СИСТЕМАХ ПРАВООХРАНИТЕЛЬНЫХ ОРГАНОВ: СОЦИОЛОГИЧЕСКИЙ АНАЛИЗ
}

\begin{abstract}
Аннотация. В странах Западной Европы и США функционирует диверсифицированная система дополнительного профессионального образования (ДПО) в системах правоохранительных органов без централизованной модели, характерной для России, что повышает возможности использования существующего многообразия форм обучения сотрудников органов внутренних дел. В статье представлен социологический анализ зарубежного опыта в данной сфере в аспекте рассмотрения и обоснования возможностей и ограничений его использования с целью повышения эффективности ДПО сотрудников органов внутренних дел РФ.

Ключевые слова: сотрудники полиции, зарубежные страны, макрорегионы, дополнительное профессиональное образование, повышение квалификации, эффективность
\end{abstract}

\begin{abstract}
Современная правоохранительная система - высокопрофессиональный социальный институт, предъявляющий исключительно высокие требования к квалификации и личным качествам как офицерского, так и рядового состава. Система профессиональной подготовки личного состава правоохранительных органов в современных развитых странах является многоуровневой и включает в себя в т.ч. институты дополнительной профессиональной подготовки и обучения. В настоящее время система дополнительного профессионального образования (ДПО) в правоохранительной сфере является самостоятельным социальным институтом, реализующим следующие функции: адаптационную (к меняющимся условиям в сфере правопорядка), мотивационную (к личностному и профессиональному развитию сотрудников), социально-коммуникационную (направленную на установление и расширение профессиональных связей с коллегами), профессиональной мобильности (вертикальной и горизонтальной), трансфера знаний (вертикального и горизонтального).
\end{abstract}

\section{Эмпирическая база исследования и методология}

Исследование представляет собой вторичный анализ современной зарубежной научной литературы, посвященной системе подготовки в правоохранительных органах отдельных стран Западной Европы и Северной Америки, на основе компаративистского анализа. Несмотря на различия между Россией и зарубежными странами с точки зрения политического устройства, социальноэкономических процессов и развитости социальных институтов, современные правоохранительные системы разных стран сталкиваются со многими общими проблемами и вызовами, способствующими формированию общих потребностей в сфере повышения квалификации. Это в т.ч. сложная и динамичная регуляторная среда, требующая постоянного обновления и совершенствова- 
ния правовых знаний; состязательный и независимый характер правосудия, требующий высокой квалификации при расследовании преступлений, сборе и представлении доказательств, аргументации в ходе судебного разбирательства; появление и распространение новых видов угроз общественной и государственной безопасности, в частности терроризма, экстремизма, киберпреступности; сложность и постоянное обновление методов и технологий, используемых при совершении преступлений, особенно актуальное в сфере кибербезопасности и в других высокотехнологичных отраслях; появление новых методов и технологий, используемых в деятельности правоохранительных органов при расследовании и профилактике правонарушений, охране общественного порядка; растуший запрос на повышение доверия граждан к правоохранительным органам, требующий развития в т.ч. психологических, социальных и коммуникационных навыков, а также способности работать в социально неоднородной среде; и др.

Наличие указанных проблем заставляет правоохранительные системы различных стран адаптироваться к новым условиям деятельности. Это вызывает закономерный интерес российских специалистов к изучению опыта, современных тенденций и направлений развития профессиональной подготовки в правоохранительной сфере развитых стран, для которых характерна высокая вовлеченность сотрудников в повышение собственной квалификации [Закатов 2017].

\section{Обзор проведенных исследований}

Основу профессиональной подготовки кадров правоохранительных органов в странах Западной Европы и Северной Америки, как и в России, составляет многоуровневая система специализированных учебных заведений. В зависимости от занимаемой должности и уровня ответственности от полицейского может требоваться либо только базовая профессиональная подготовка, либо высшее или послевузовское образование. Продвижение по служебной лестнице, как правило, требует повышения образовательного уровня либо путем получения соответствующего формального образования следующего уровня, либо через систему ДПО. Эффективным примером такой многоуровневой целостной системы профессиональной подготовки в Европе является Германия. В немецкой системе выделяются 3 уровня подготовки [Isaeva 2018]. Низший уровень образован школами земельной полиции и школами военизированной полиции, где обучение по 1-1,5-годовой программе дает среднее специальное образование и допуск к службе на позициях среднего начальствующего состава. Второй уровень образования - это 3-летнее обучение на специальных кафедрах полиции в вузах государственного управления или высших школах полиции. Поступление в эти учебные заведения требует наличия либо среднего специального, либо высшего профессионального образования. Третий, высший, уровень профессиональной подготовки - это прохождение годовой программы обучения в земельных или федеральных высших школах полиции, а также обязательное обучение в высшей школе полиции ФРГ - Deutsche Hochschule der Polizei ( $\mathrm{DHPol}$ ). Последняя является высшим звеном профессиональной подготовки полицейских кадров и центром компетенций для федеральной полиции - ядра правоохранительной системы Германии.

Особое значение с точки зрения развития новых компетенций, необходимых для соответствия полиции меняющимся условиям и угрозам, имеют 3 специальных элемента в структуре DHPol: институт полицейских технологий, подразделение координации исследований в области полицейской безопасности, управление политического образования в полиции. Обучение в DHPol в 
значительной мере рассматривается именно как повышение квалификации. Программа подготовки кадров на 2019 г. включает в себя 3 основных направления профессионального развития: 1) лидерство, организационные и административные процессы; 2) оперативное управление, транспорт, логистика; $3)$ уголовное право и юриспруденция ${ }^{1}$. Помимо групп полноценных курсов и мероприятий, курируемых различными кафедрами DHPol, слушателям предлагается целый ряд специализированных междисциплинарных тренингов. Таким образом, деятельность крупнейшей германской полицейской образовательной организации характеризуется высоким тематическим разнообразием предлагаемых курсов повышения квалификации и других специализированных мероприятий.

При всей важности $D H P o l$ в системе дополнительной профессиональной подготовки полицейских Германии, она является лишь ее высшим звеном. Само же повышение квалификации для всех категорий работников правоохранительных органов является повсеместным и универсальным, всячески поощряется руководством и является одновременно возможностью и необходимостью для сотрудников. Это могут быть централизованные курсы повышения квалификации, которые действуют в каждой федеральной земле ФРГ 2 , а также и децентрализованные формы повышения квалификации при полицейских управлениях и возможности электронного обучения. Поощряется самостоятельное участие в различных курсах и тренингах, которые соответствуют потребностям конкретного сотрудника и определяются содержанием его профессиональной деятельности.

Определение содержания и форматов обучения в значительной степени зависит от самого сотрудника; их финансирование, как правило, берет на себя государство. Возможность повышения квалификации существует не только в полицейских академиях или при управлениях полиции, но и за пределами правоохранительной системы Германии. Активно поощряется международное сотрудничество и компетентность работников полиции Германии. Многоуровневое и непрерывное развитие и повышение эффективности человеческого и социального капиталов сотрудников правоохранительных органов, финансовая поддержка повышения их квалификации со стороны государства определяют высокий уровень профессионализма немецкой полиции и эффективность института ДПО в ФРГ.

В Великобритании система подготовки полицейских кадров также носит многоуровневый характер, и включает в себя 1) региональные учебные центры, осуществляющие первоначальную подготовку и 2) колледж высшего полицейского состава. Специалисты отмечают преимущественно практическую направленность британской системы профессиональной подготовки: умение общаться, рассуждать, логично мыслить, слушать собеседника, проявлять тактичность, находить подход к людям и устанавливать контакты с ними, вызывать доверие, уметь допрашивать свидетелей и др. [Васенин, Денисов 2014]. То есть, в профессиональной подготовке сотрудников упор делается на развитие общих когнитивных и коммуникативных навыков. Освоение более специальных знаний и навыков при этом осуществляется в значительной мере в ходе специальных дополнительных программ. Потребности в росте профессионализма на разных уровнях служебной иерархии очевидны и требуют, по мнению

\footnotetext{
1 Jahresfortbildungsprogramm 2019. Münster: Deutsche Hochschule der Polizei. 2019. URL: https://www. dhpol.de/JFP_2019.pdf (проверено 20.05.2019).

2 Weiterbildung. - Polizei Niedersachsen. 2019. URL: https://polizei-studium.de/weiterbildung (проверено 21.05.2019)
} 
авторов, более тесной связи между университетами и практикой полицейской деятельности.

Для стран Северной Америки (Канада и США) характерна более сложная и децентрализованная система профессиональной подготовки правоохранителей, связанная во многом с особенностями федеративного устройства и высокой степенью самостоятельности местных и региональных звеньев правоохранительной системы. В Канаде, где образование полицейских является практикоориентированным, выделяются 3 разные модели профессиональной переподготовки. Первая - внутренняя, или локальная: обучение непосредственно в подразделениях полиции крупных городов в форме передачи опыта; вторая - централизованная программа подготовки - предполагает прохождение обучения с отрывом от службы в полицейских академиях и колледжах. Третья комплексная программа подготовки, - в отличие от предыдущих, является гораздо более длительной, до 3 лет, и включает, помимо практических, также и теоретические занятия. Прохождение таких курсов является необходимым этапом подготовки для сотрудников специальных служб и руководящего состава полиции [Васенин, Денисов 2014].

Для США характерна не только развитая система образовательных учреждений на различных уровнях правоохранительной системы (федеральный, муниципальный, уровень штата), но и активное взаимодействие с гражданской образовательной системой. Подготовка полицейских кадров зачастую осуществляется непосредственно на местах, что обусловливает высокое разнообразие ее конкретных форм и моделей. Кадровое обеспечение полиции и других служб зачастую основано на рекрутинге специалистов из гражданской сферы и их «доучивании» за счет дополнительной подготовки. Это делает роль различных форм ДПО ключевым элементом профессиональной подготовки американских полицейских, особенно на низшем и среднем уровнях. В профессиональной подготовке и переподготовке полицейских кадров большую роль играют частные учебные заведения и организации, принадлежащие штатам и муниципалитетам, которые обладают высокой самостоятельностью и определяют содержание программ в соответствии со своими потребностями. Следствием этого стала чрезвычайно широкая сеть учебных заведений, вовлеченных в профессиональную подготовку полицейских. Так, по данным Министерства юстиции США по состоянию на 2016 г., в 2013 г. в стране действовали 664 академии местного уровня и уровня штата, обеспечивающие начальную полицейскую подготовку [Reaves 2016]. Помимо учебных заведений местного и регионального уровня, в США действуют и специализированные федеральные учебные заведения, обучение в которых, как правило, требуется для работников федеральных служб, прежде всего ФБР. Такие организации объединены в сеть федеральных центров подготовки работников правоохранительных органов (FLETC), находящихся в ведении Министерства внутренней безопасности США. FLETC является крупнейшим центром непрерывного обучения и переподготовки работников правоохранительной системы США, обслуживающим более 90 федеральных агентств и предлагающим большое число узкоспециализированных программ, которые могут осуществляться как в центрах подготовки, так и за их пределами, в т.ч. по месту службы. Всего по состоянию на апрель 2019 г. каталог FLETC включал в себя 84 программы ${ }^{1}$. Анализ каталога показывает его крайне высокую специализацию и адаптацию к новым потребностям и угрозам, требующим новых компетенций от офицеров полиции.

1 Search the Training Catalog. - FLETC. 2019. URL: https://www.fletc.gov/training-catalog (accessed 22.05.2019). 
Американская система профессиональной подготовки полицейских кадров является во многом уникальной. В подавляющем числе случаев от сотрудников полиции не требуется специального высшего образования, а обретение необходимых знаний и практических навыков осуществляется с активным участием частных и общественных учебных заведений. Одновременно на федеральном уровне созданы центры узкоспециальных компетенций, которые обеспечивают профессиональную подготовку в соответствии с меняющимися условиями и потребностями. В этом аспекте деятельность FLETC во многом аналогична работе высшей школы $\mathrm{DHPol}$ в Германии.

\section{Обсуждение и выводы}

Сравнительно-исторический анализ современной литературы, посвященной системе подготовки в правоохранительных органах разных стран, позволяет выделить несколько общих моментов, характеризующих основные тенденции и проблемы в этой сфере. Во-первых, большинство специалистов отмечают растущую потребность в дополнительной профессионализации полиции и необходимость более тесной интеграции полицейской деятельности и системы высшего образования, в научно-практическом обосновании новых методов и технологий работы полиции [Paterson 2011]. При этом такая интеграция сопряжена с определенными сложностями из-за различий в социальных институтах образования и правоохранительной деятельности. Во многих случаях полицейские органы ориентированы преимущественно на практическую подготовку, которая может осуществляться непосредственно внутри полиции, тогда как образование с высокой составляющей академических, фундаментальных знаний и исследовательской работы считается избыточным. Тем не менее рост потребности в профессионализации, в т.ч. за счет эффективного взаимодействия с ведомственными и гражданскими вузами, считается во многих странах Западной Европы, Северной Америки стратегическим направлением развития. Во-вторых, дополнительная подготовка и обучение считаются неотъемлемыми элементами профессионализации, а ключевыми факторами успеха соответствующих программ являются специализация и адаптивность. Примеры наиболее успешных с точки зрения ДПО стран, таких как Германия и США, показывают, что дополнительное образование должно быть разнообразным как по форме, так и по содержанию, сфокусированным на конкретных знаниях и компетенциях, необходимых различным категориям сотрудников, и отвечать меняющимся условиям несения службы и угрозам общественной безопасности. Желаемые изменения в системе профессиональной подготовки также связываются с необходимостью менять педагогические подходы и, в частности, ориентироваться на принципы андрагогики (образования взрослых), а также философию полицейской деятельности, в которой ключевую роль играют проблемная ориентированность и взаимодействие с локальными сообществами [White, Escobar 2008]. В-третьих, можно отметить тематические области в работе правоохранительных органов, которые привлекают устойчивый и растущий интерес. К ним относятся курсы и другие мероприятия, связанные с освоением новых видов технологий, контртеррористической деятельностью, проведением публичных мероприятий, эффективным взаимодействием с обществом и умением работать в поликультурной среде. В большинстве развитых стран последним двум пунктам уделяется особое внимание. Поскольку полиция рассматривается прежде всего как общественный институт, умение сотрудников полиции разного уровня взаимодействовать с гражданами, меньшинствами и общественностью становится ключевой компетенцией, позволяющей решать вполне конкретные профессиональные задачи, такие как опрос 
свидетелей, допрос подозреваемых, профилактика правонарушений в специфических социальных контекстах. Рост значения подобных компетенций очевиден в США и странах ЕС, которые в настоящее время переживают очередную волну миграционного кризиса. В-четвертых, в системе профессиональной подготовки западных стран, как и правоохранительной системе в целом, значительно возрастает роль международной кооперации. Это особенно очевидно и актуально для стран Евросоюза, которые стремятся создавать общее образовательное пространство и площадки для обмена опытом и взаимодействия правоохранителей в целях повышения собственных компетенций, распространения лучших практик и налаживания эффективных каналов коммуникации. Ключевую роль в этих попытках играет Европейский полицейский колледж $(C E P O L)$, имеющий статус агентства при Евросоюзе и обеспечивающий международное сотрудничество офицеров полиции стран $\mathrm{EC}^{1}$. CEPOL регулярно организует специализированные курсы, семинары, конференции, программы обмена, управляет специальной образовательной платформой в сети Интернет, бесплатной для полицейских стран-участниц. Требования к эффективности полицейских подразделений и ограниченные бюджеты, а также конкуренция со стороны корпоративного сектора заставляют правоохранительные органы инвестировать в т.ч. в курсы по менеджменту и развитию навыков эффективного лидерства [Voronov, Petrova, Račko 2006].

Современные тенденции развития образовательных моделей в территориальных правоохранительных системах развитых зарубежных стран, таким образом, при всем своем разнообразии характеризуются общими чертами и проблемами. Поскольку российская правоохранительная система сталкивается с аналогичными проблемами (появление новых технологий, потребность в эффективном менеджменте, необходимость работать в усложняющейся социальной и культурной среде, рост запроса на выстраивание доверительных отношений с обществом и др.), изучение опыта индустриально развитых стран становится актуальной и востребованной задачей по использованию апробированных многоуровневых технологий ДПО. Целесообразно не ограничиваться существующим взаимодействием российской правоохранительной системы и международных полицейских сил по линии Интерпола, а сосредоточить дополнительные усилия на изучении опыта территориального профессионального полицейского образования зарубежных стран с целью повышения эффективности ДПО российской полиции.

\section{Список литературы}

Васенин А.Ю., Денисов С.Л. 2014. Опыт подготовки специалистов в полиции зарубежных стран. - Новое слово в науке: перспективы развития. № 1. С. 311-314.

Закатов В.В. 2017. Профессиональная подготовка сотрудников полиции за рубежом: особенности и тенденции развития. - Балтийский гуманитарный журнал. № 4(21). С. 313-315.

Isaeva I. 2018. Police Training in the System of Professional Training for Federal Police Force in Germany. - Comparative Professional Pedagogy. Vol. 8. Is. 4. P. 54-59.

Paterson C. 2011. 'Adding value?' A Review of the International Literature on the Role of Higher Education in Police Training and Education. - Police Practice and Research. Vol. 12. Is. 4. P. 286-297.

Reaves B.A. 2016. State and Local Law Enforcement Training Academies, 2013. -

\footnotetext{
${ }^{1}$ CEPOL: Types of Learning. - CEPOL. 2019. URL: https://www.cepol.europa.eu/education-training/ourapproach/types-learning (accessed 23.05.2019).
} 
Bureau of Justice Statistics, U.S. Department of Justice. July 2016. URL: https://www. bjs.gov/content/pub/pdf/slleta13.pdf (accessed 21.05.2019).

Voronov V., Petrova I., Račko E. 2006. Reǵionālās ekonomikas konkurētspējas paaugstināšana un aktī̄ā adaptācija globalizācijas apstākḷos. Daugavpils. 120 p.

VORONOV Victor Vasil'evich, Dr.Sci. (Soc.), Professor; Leading Researcher of the Sociological Institute - branch of the Federal Center of Theoretical and Applied Sociology, Russian Academy of Sciences (bld. 5, 24/35 Krzhizhanovskogo St, Moscow, Russia, 117218; voronov@isras.ru)

SHULEPIN Mikhail Vladimirovich, postgraduate student of the Sociological Institute - branch of the Federal Center of Theoretical and Applied Sociology, Russian Academy of Sciences (bld. 5, 24/35 Krzhizhanovskogo St, Moscow, Russia, 117218; mihailshulepin@mail.ru)

\title{
ABOUT ADDITIONAL PROFESSIONAL EDUCATION IN FOREIGN TERRITORIAL SYSTEMS OF LAW ENFORCEMENT AGENCIES: SOCIOLOGICAL ANALYSIS
}

\begin{abstract}
In Western Europe and the United States, there is a diversified system of additional professional education (APE) in law enforcement systems without a centralized model specific to Russia, which increases the possibility of using the existing variety of forms of training of internal affairs officers. The article presents a sociological analysis of foreign experience in this field in the aspect of consideration and justification of the possibilities and limitations of its use in order to improve the efficiency of APE of employees of the internal affairs bodies of the Russian Federation.

Keywords: police officers, foreign countries, macro-regions, additional professional education, professional development, efficiency
\end{abstract}

